\title{
Kurva Histeresis Bahan Feromagnetik Co0.8Pt0.2 pada Tiga Daerah Domain
}

\author{
Irmawati Hasanah ${ }^{1}$, Lutfi Rohman ${ }^{1}$, Edy Supripyanto ${ }^{1}$ \\ 1 Jurusan Fisika, FMIPA, Universitas Jember, Jember 68121, Jawa Timur, Indonesia \\ e-mail: irmawatihasanah10031997@gmail.com
}

\begin{abstract}
Abstrak
Bahan magnetik alloy Co0.8Pt0.2, merupakan bahan yang mempunyai konstanta anisotropi dan tahanan korosi yang tinggi sehingga bisa dijadikan pembuatan hardisk dengan kapasitas penyimpanan yang besar pada ukuran nanometer. Ukuran kritis bahan CoPt dianalisis dengan grafik hubungan rapat energi dengan ukuran sisi kubus yang terdapat tiga zona domain, yakni single domain, transisi dan multi domain. Nilai ukuran kritis yang dihasilkan sebesar $20 \mathrm{~nm}$, nilai tersebut dilihat dari titik akhir dari zona single domain yang akan menuju ke zona transisi. Kurva histerisis bahan CoPt ini menghasilkan medan koersivitas yang kecil yaitu seperti halnya magnet dalam golongan soft magnet. Penelitian ini mengkaji sifat magnetik bahan CoPt dalam bentuk nanocube menggunakan kurva histerisis dan ukuran kritis yang dikaji dalam bentuk grafik hubungan rapat energi $(\mathrm{KJ} / \mathrm{m} 3)$ dengan ukuran sisi kubus $(\mathrm{nm})$ yang dilakukan dengan memvariasikan ukuran bahan. Ukuran kritis dapat ditinjau dengan membaginya dalam tiga zona yakni single domain, transisi dan multi domain. Nilai ukuran kritis bahan sebesar $20 \mathrm{~nm}$. Kurva histerisis pada zona single domain dengan sisi kubus $8 \mathrm{~nm}$ medan koersivitas bernilai 3,46×10$7 \mathrm{~T}$, pada zona transisi $20 \mathrm{~nm}$ medan koersivitas yang dihasilkan sebesar 9,43×10-7 T sedangkan pada multi domain $29 \mathrm{~nm}$ medan koersivitas yang dihasilkan bernilai 1,5×10-6 T.
\end{abstract}

Kata Kunci: CoPt, Ukuran Kritis, Kurva histerisis, nanocube, magnetisasi saturasi.

Hysteresis Curves of Co 0.8Pt0.2 Ferromagnetic Material in Three Domain Regions

\begin{abstract}
The magnetic alloy material Co0.8Pt0.2, is a material that has a high anisotropy constant and corrosion resistance so that it can be made into a hard disk with a large storage capacity at nanometer size. The critical size of CoPt material is analyzed by the graph of the relationship of energy density with the size of the side of the cube which has three domain zones, namely single domain, transition and multi domain. The resulting critical size value is $20 \mathrm{~nm}$, the value is seen from the endpoint of the single domain zone that will go to the transition zone. The hysteresis curve of the CoPt material produces a small coercivity field that is like a magnet in the soft magnet group. This study examines the magnetic properties of CoPt material in the form of nanocubes using hysteresis curves and critical sizes which are examined in the form of a graph of the relationship of energy density $(\mathrm{KJ} / \mathrm{m} 3)$ with the size of the side of the cube $(\mathrm{nm})$ which is done by varying the size of the material. Critical measures can be reviewed by dividing them into three zones namely single domain, transition and multi domain. The critical size value of the material is $20 \mathrm{~nm}$. The hysteresis curve in a single domain zone with an $8 \mathrm{~nm}$ cube side of the coercivity field was $3,46 \times 10-7 \mathrm{~T}$, in the $20 \mathrm{~nm}$ transition zone the resulting coercivity field was $9,43 \times 10-7 \mathrm{~T}$ while in the multi domain $29 \mathrm{~nm}$ the resulting coercivity field was worth $1,5 \times 10$ 6.
\end{abstract}

Keywords: CoPt, Critical Size, Hysteresis Curve, nanocube, saturation magnetization

How to Cite: H, Irmawati., R, Lutfi., S, Edy. (2020). Kurva Histeresis Bahan Feromagnetik Co0.8Pt0.2 pada Tiga Daerah Domain. J urnal Pendidikan F isika dan Keilmuan (J PFK), 6(1), 4754. doi: https://doi.org/10.25273/jpfk.v6i1.5236 


\section{PENDAHULUAN}

Teknologi pembuatan material magnetik telah berkembang sampai upaya pembuatan piranti magnetik dalam ukuran mikro hingga berskala nanometer. Perkembangan teknologi tersebut ditandai dengan gencarnya penelitian material magnetik untuk mengetahui sifat-sifat dari bahan magnetik. Aplikasinya dalam bidang teknologi informasi yaitu pemakaian bahan feromagnetik berskala nanometer sebagai media penyimpan data(Piramanayagam, 2007). Media penyimpan data yang biasa digunakan adalah media perekam magnetik Hard Disk Drive (HDD). Hard Disk Drive (HDD) digunakan sebagai media penyimpanan data jangka panjang pada komputer modern. HDD merupakan perangkat media perekam magnetik yang diciptakan pertama kali oleh IBM dengan nama RAMAC (Random Acces Method of Accounting and Control) (Widodo, 2013).

Bahan feromagnetik adalah bahan yang mempunyai kemampuan tinggi untuk membentuk medan magnet di dalam bahan tersebut, dengan bentuk: partikel, disk, wires serta dapat digunakan sebagai media penyimpan data dengan cara memanfaatkan sifat domain magnet di dalam feromagnetik. Material feromagnetik merupakan bahan yang memiliki nilai suseptibilitas magnetik besar yang bernilai positif. Sifat ferromagnetik muncul dalam bahan yang atom-atomnya memiliki momen magnetik permanen yang berinteraksi satu sama lainnya secara kuat dan mampu mempertahankan sifat-sifat magnetik setelah magnet luarnya dihilangkan (Dedi, 2013). Selain itu, bahan feromagnetik merupakan bahan yang memiliki resultan medan atomik terbesar yang disebabkan oleh momen spin elektron. Spin elektron yang tidak berpasangan akan menimbulkan medan magnetik sehingga total medan magnetik yang dihasilkan oleh suatu atom menjadi lebih besar(Nazah, 2017). Spin elektron dan momen magnet bahan feromagnetik tersusun teratur karena adanya momen magnet spontan yang diberi medan magnet eksternal bernilai nol (Yani et al., 2019).

Bahan magnetik alloy $\mathrm{Co}_{1-\mathrm{x}} \mathrm{Pt}_{\mathrm{x}}$ (Cobalt-Platinum) pada komposisi Pt sebesar 0,2 atau dapat dituliskan menjadi $\mathrm{Co}_{0.8} \mathrm{Pt}_{0.2}$, telah banyak mendapatkan perhatian oleh peneliti maupun ilmuwan fisika, karena CoPt merupakan bahan yang mempunyai konstanta anisotropi dan tahanan korosi yang tinggi (Hosoiri dkk, 2003). CoPt memiliki konstanta anisotropi dan tahan korosi yang tinggi maka bahan ini bisa dijadikan pembuatan hardisk dengan kapasitas penyimpanan yang besar pada ukuran nanometer. Sifat-sifat bahan yang dianalisis adalah suseptibilitas dan medan-medan yang terdapat dalam bahan tersebut yaitu medan koersivitas, medan magnet dan medan saturasi (Hosoiri et al., 2003; Mardiansyah, 2014; Sun et al., 2004).

Penelitian sebelumnya pada tahun Widodo (2013) telah melakukan pengamatan stuktur domain magnet pada kondisi groundstate. Di dalam penelitiannya, diameter kritis bahan berbentuk bola pada keadaan groundstate telah diperoleh pada masing-masing material feromagnetik. Analisa diameter kritis dilakukan berdasarkan pengamatan keadaan struktur domain yang terbentuk. Selanjutnya dilakukan analisa terhadap energi sistem yang berkontribusi pada keadaan tersebut. Pengamatan struktur domain magnet pada keadaan tanpa medan magnet eksternal (zero field) lebih difokuskan pada bentuk struktur domain yang stabil setelah mencapai energi minimum. Terdapat hubungan antara profil energi sistem yang dihasilkan terhadap stuktur domain stabil yang terbentuk. Analisa dari profil energi sistem lebih difokuskan pada perubahan yang terjadi dari profil energi exchange dan energi demagnetisasi terhadap variasi diagonal (Widodo, 2013). Selanjutnya, menurut Nazah (2017) bahwa variasi komposisi

J urnal Pendidikan Fisika dan Keilmuan (J PFK), Vol. 6, No. 1, Maret 2020, 47-54. 
mempengaruhi nilai dari temperatur curie, semakin besar komposisi Co yang diberikan maka temperatur curie yang dihasilkan semakin tinggi. Hal ini terjadi karena unsur Co merupakan material feromagnetik sedangkan unsur $\mathrm{Pt}$ merupakan material paramagnetik (Nazah, 2017).

Berdasarkan uraian di atas maka pada penelitian ini akan diteliti sifat magnetik bahan feromagnetik CoPt dengan variasi ukuran sisi kubus, komposisi Co1-xPtx dibuat tetap pada $\mathrm{x}=0,2$ dan berbentuk nanocube, serta dilakukan dengan metode simulasi mikromagnetik NMAG. Pada penelitian ini akan dianalis zona konfigurasi spin magnetik berdasarkan ukuran sisi dalam bentuk nanocube. Setelah didapatkan zona konfigurasi spin magnetik maka akan diperoleh kurva histerisis bahan CoPt. Penelitian simulasi mikromagnetik ini dengan bahan feromagnetik CoPt akan diaplikasikan sebagai penyimpan data menggunakan software NMAG yang hanya dapat dijalankan dalam sistem operasi Linux. NMAG berbasiskan Metode Finite Element (metode elemen hingga).

\section{METODE PENELITIAN}

Simulasi mikromagnetik ini dilakukan di Jurusan Fisika, Fakultas Matematika dan IImu Pengetahuan Alam, Universitas Jember. Penelitian simulasi mikromagnetik ini diawali dengan studi pustaka dari beberapa sumber berupa buku, jurnal ilmiah, skripsi, dan tesis. Hal ini dilakukan untuk observasi terhadap topik penelitian. Kemudian dilakukan penginstallan software pada komputer. Software yang digunakan dalam penelitian simulasi mikromagnetik ini adalah program NMAG, software MayaVi, Origin dan Netgen. Setelah software terinstall dan siap digunakan maka dilakukan kegiatan simulasi, simulasi dilakukan dengan membuat file bahan yang berisi parameter input bahan alloy CoPt (.py) yaitu Ms (magnetisasi saturasi), K (konstanta anisotropi), A (konstanta exchange), dan konstanta damping.

Selain parameter input yang ada diatas, juga membuat parameter input berupa bentuk dan ukuran geomteri (.geo). Kedua file tersebut ditempatkan dalam satu folder, kemudian dilakukan running simulasi pada terminal Linux dengan program NMAG. Setelah melakukan running maka didapatkan file berupa (.vtk) untuk visualisasi MayaVi dan file berupa (.ndt) digunakan untuk visualisasi grafik dan kurva histerisis dalam program Origin. Simulasi mikromagnetik ini dijalankan dengan menentukan ukuran kritis pada zona single domain, multi domain, dan transisi serta menganalisa kurva histerisis pada bahan CoPt. Kemudian dari data output yang ada dilakukan analisis selanjutnya hasil analisis yang didapatkan dapat membuat kesimpulan.

\section{HASIL DAN PEMBAHASAN}

Domain magnetik mempresentasikan zona-zona yang ada pada bahan feromagnetik yang memiliki momen magnetik sejajar. Pengamatan struktur domain magnet pada keadaan tanpa medan magnet eksternal (zero field) lebih difokuskan pada bentuk struktur domain yang stabil setelah mencapai energi minimum (groundstate). Terdapat hubungan yang erat antara profil rapat energi yang dihasilkan terhadap struktur domain stabil yang terbentuk. Analisa dari profil rapat energi lebih dititik beratkan pada perubahan yang terjadi dari profil energi exchange dan energi demagnetisasi terhadap variasi sisi. Pengamatan profil rapat energi ini mempertegas keadaan struktur domain yang terbentuk. Pada keadaan single domain yaitu ketika energi demagnetisasi lebih mendominasi dibandingkan energi exchange. Dan pada keadaan multi domain yaitu energi exchange lebih dominan. 
Struktur domain yang berubah dari single domain menjadi multi domain yaitu menunjukkan bahwa ukuran dari bahan feromagnetik melewati ukuran kritisnya yang dikenal sisi kritis.

Hasil simulasi mikromagnetik yang dilakukan, diperoleh dua struktur domain magnet pada model nanocube, single domain dan multi domain. Dari hasil pengamatan ditemukan adanya transisi struktur domain dari single domain menjadi multi domain. Batas ukuran transisi bahan feromagnetik berbentuk kubus inilah yang dikenal sebagai sisi kritis. Sisi kritis dapat didefinisikan sebagai ukuran sisi maksimum dari keadaan single domain bahan feromagnetik yang berbentuk kubus. Struktur domain teramati dalam keadaan single domain yaitu pada saat di bawah sisi kritis, , sedangkan multi domain ditemukan di atas sisi kritis. Berdasarkan hasil analisa yang dilakukan terhadap profil rapat energi pada saat di bawah sisi kritis, profil rapat energi didominasi oleh energi demagnetisasi, kemudian di atas sisi kritis, energi exchange beranjak naik dan selanjutnya mendominasi profil rapat energi. Analisa profil rapat energi ini sesuai dengan keadaan struktur domain yang dihasilkan. Secara keseluruhan, hasil simulasi mikromagnetik ini menunjukkan bahwa sisi kritis yang diperoleh sesuai dengan prediksi hasil perhitungan teori.

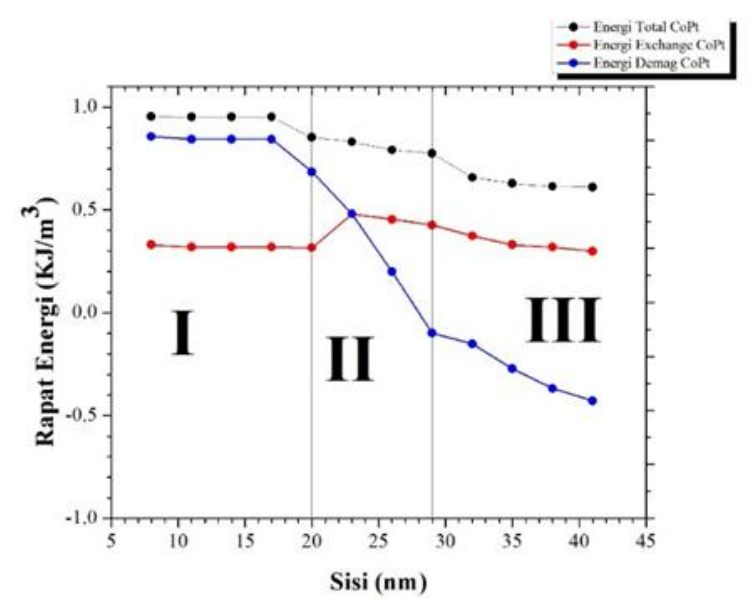

Gambar 1. Grafik Hubungan Rapat Energi dengan Sisi Kubus

Berdasarkan hasil simulasi, profil energi sistem yang teramati pada bahan CoPt dapat dibagi menjadi tiga bagian, seperti pada Gambar 1. Bagian pertama adalah zona profil energi sistem dengan keadaan energi demagnetisasi mendominasi dibandingan energi exchange. Keadaan ini terjadi dimulai dari sisi 8 $\mathrm{nm}$ sampai dengan $20 \mathrm{~nm}$. Pada zona ini, struktur domain stabil yang terbentuk adalah single domain. Jadi sisi $20 \mathrm{~nm}$ adalah sisi kritis dari bahan CoPt. Bagian kedua adalah zona transisi. Zona ini terletak pada rentang sisi $8 \mathrm{~nm}$ hingga $29 \mathrm{~nm}$. Pada rentang zona ini, profil energi exchange cenderung beranjak naik seiring dengan bertambahnya ukuran sisi pada kubus. Sedangkan yang terakhir merupakan zona bagian ketiga, yakni zona energi stabil, terletak di atas zona energi transisi, $29 \mathrm{~nm}$ hingga $41 \mathrm{~nm}$. Profil rapat energi pada rentang ini didominasi oleh energi exchange. Keadaan profil rapat energi yang teramati ini sesuai dengan keadaan struktur domain yang terbentuk, yaitu multi domain yang merupakan keadaan struktur domain pada rentang zona ini. Sedangkan pengamatan yang dilakukan terhadap orientasi dari arah struktur multi domain yang terbentuk, menunjukkan bahwa pada bahan CoPt pada rentang sisi $29 \mathrm{~nm}$ hingga $41 \mathrm{~nm}$ secara keseluruhan pada EAO (Easy Axis Oriented). 
Berdasarkan hasil simulasi dalam penentuan sisi kritis bahan CoPt yang ditunjukkan oleh Gambar 1, diperoleh hasil bahwa sesuai dengan perhitungan secara teori yaitu menggunakan persamaan Brown. Sisi kritis pada hasil simulasi sebesar $20 \mathrm{~nm}$ dan pada perhitungan secara teori sebesar $20.34 \mathrm{~nm}$. Hasil simulasi juga menunjukkan bahwa semakin besar nilai Magnetisasi saturasi, maka nilai energi totalnya juga semakin besar seperti yang ditunjukkan pada grafik hubungan rapat energi dengan sisi Gambar 4.

Penelitian selanjutnya adalah mengamati nilai medan eksternal yang dapat terlihat pada kurva histeresis. Selain medan eksternal, kurva histeresis ini akan memberikan informasi mengenai zona saturasi dan remanensi. Zona saturasi adalah zona yang mengalami perubahan sekalipun medan koersivitas diperbesar yang ditandai dengan adanya struktur domain berupa single domain. Zona remanensi (sisa) adalah magnetisasi sisa ketika medan koersivitas magnetik ditiadakan $(\mathrm{H}=0)$.

Kurva histeresis yang diperoleh selanjutnya dianalisis guna menentukan besar medan koersivitas dari masing-masing variasi sisi bahan CoPt dari pengaruh medan eksternal pada zona single domain, transisi, dan multi domain. Medan koersivitas adalah zona ketahanan bahan magnetik untuk mengubah magnetisasinya. Medan eksternal yang diberikan pada kurva histeresis dengan rentang sebesar 1.26 T (10 A/m) diperkecil sampai -1.26 T (-10 A/m).

Ukuran sisi kubus pada bahan $\mathrm{CoPt}$ yang digunakan untuk mengetahui pengaruh perubahan medan eksternal dengan rentang -1.26 T sampai $1.26 \mathrm{~T}$ adalah $8 \mathrm{~nm}$, $20 \mathrm{~nm}$, dan $29 \mathrm{~nm}$. Ukuran sisi kubus tersebut mewakili sisi yang diambil dari setiap bagian pada kurva histeresis yaitu single domain, transisi dan multi domain saat energi stabil. Perubahan medan eksternal tersebut terlihat pada Gambar 2, Gambar 3 dan Gambar 4.

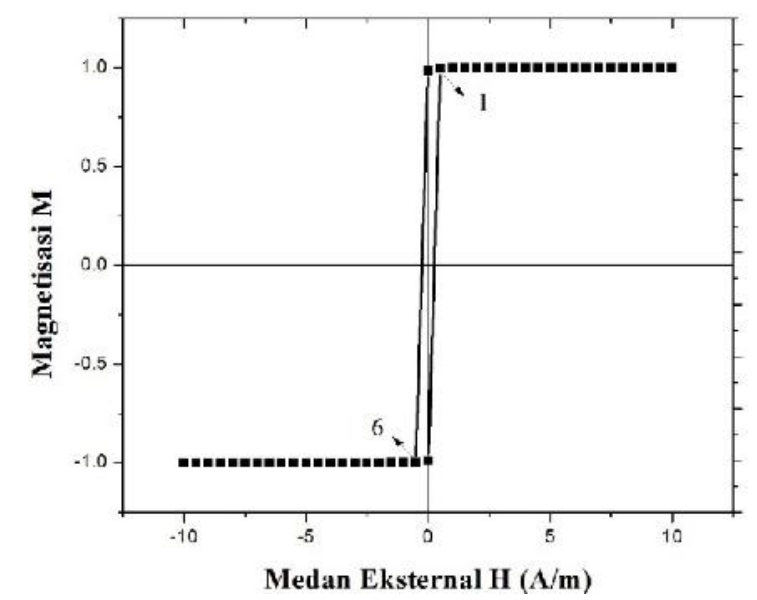

Gambar 2. Kurva histerisis bahan CoPt dengan sisi kubus $8 \mathrm{~nm}$ (zona single domain )

Kurva histeresis magnetisasi terhadap medan magnet eksternal yang diberikan, disajikan pada Gambar 2. Dari hasil simulasi memperlihatkan bahwa saat diberikan medan eksternal, medan saturasi mengalami pembalikan magnetisasi yaitu sebesar $6.15 \times 10^{-7} \mathrm{~T}$ atau $0.49 \mathrm{~A} / \mathrm{m}$. Berdasarkan hasil simulasi kurva histerisis, sifat-sifat magnetik bahan $\mathrm{CoPt}$ dalam keadaan tidak termagnetisasi $(\mathrm{M}=0)$ dengan diberikannya medan eksternal $0.275 \mathrm{~A} / \mathrm{m}$ atau $3.46 \times 10^{-7} \mathrm{~T}$ yang biasa disebut medan koersivitas. Hal ini menunjukkan bahwa bahan CoPt diklasifikasikan ke dalam material soft magnetic karena memiliki nilai 
medan koersivitas di bawah $1 \mathrm{~T}$. Medan koersivitas yang diperoleh dalam hal ini cukup kecil, sehingga dapat dikatakan bahwa bahan CoPt ini sulit untuk termagnetisasi. Sehingga dapat dikatakan bahan ini termasuk soft magnet.

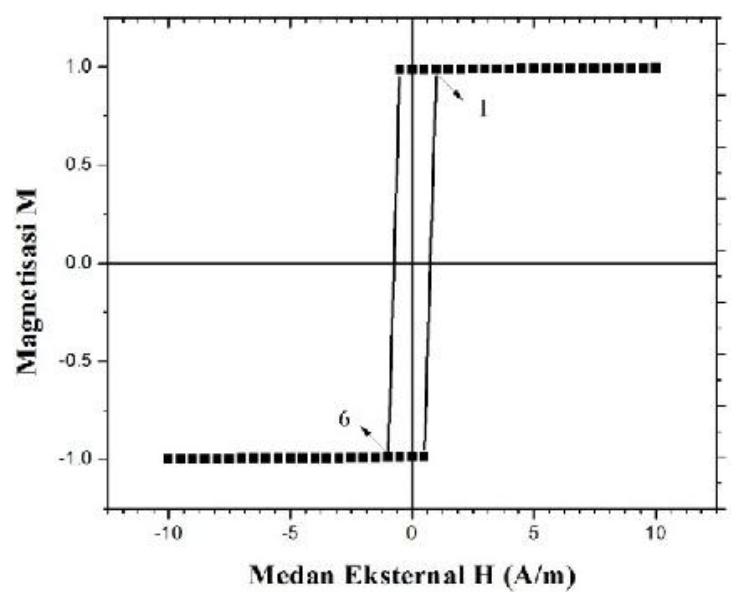

Gambar 3. Kurva histerisis bahan CoPt dengan sisi kubus 20 nm (zona transisi)

Hasil simulasi Gambar 3 memperlihatkan bahwa medan saturasi mengalami pembalikan magnetisasi saat diberikan medan eksternal, yaitu sebesar sebesar $0.99 \mathrm{~A} / \mathrm{m}$ atau $1.24 \times 10^{-6} \mathrm{~T}$. Hasil simulasi kurva histerisis, sifat magnetik bahan CoPt dalam keadaan tidak termagnetisasi atau berada pada magnetisasi nol $(M=0)$ dengan nilai medan eksternal $0.75 \mathrm{~A} / \mathrm{m}$ atau $9.43 \times 10^{-7} \mathrm{~T}$. Medan Eksternal ini juga disebut medan koersivitas. Hal ini menunjukkan bahwa bahan CoPt diklasifikasikan ke dalam material soft magnetic karena memiliki nilai medan koersivitas lebih kecil dari $1 \mathrm{~T}$ (Wahyuningsih, 2018).

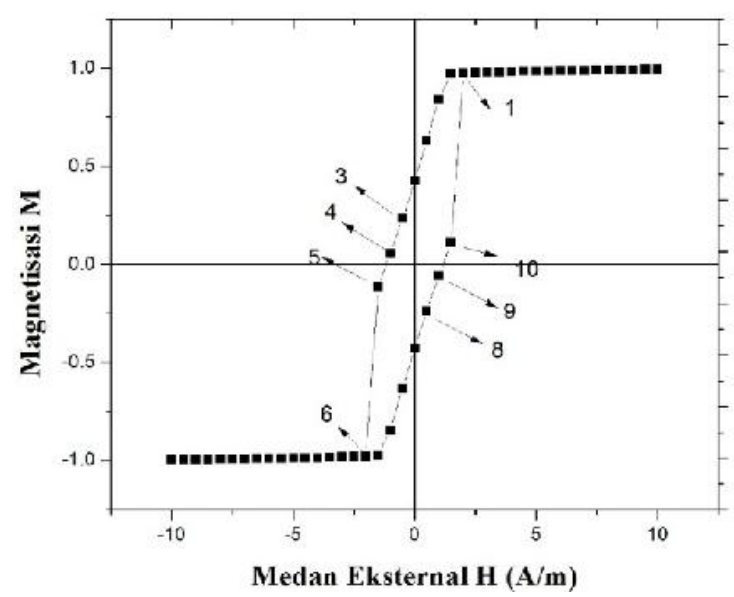

Gambar 4. Kurva histerisis bahan CoPt dengan sisi kubus 29 nm (zona multi domain)

Kurva histerisis pada Gambar 4 menjelaskan proses pembalikan magnetisasi pada bahan CoPt dengan multi domain. Pada bahan CoPt dengan ukuran sisi kubus di atas sisi kritis akan mengalami pembalikan magnetisasi model curling. Medan koersivitasnya sebesar $1.2 \mathrm{~A} / \mathrm{m}$ atau $1.5 \times 10^{-6} \mathrm{~T}$. Sedangkan medan saturasi saat mengalami pembalikan sebesar $1.9 \mathrm{~A} / \mathrm{m}$ atau $2.4 \times 10^{-6} \mathrm{~T}$. Hal ini menunjukkan bahwa ukuran sisi diatas sisi kritis termasuk ke dalam soft magnet disebabkan karena bahan ini sulit dimagnetisasi. 
Tabel 1. Medan koersivitas dan medan saturasi terhadap perubahan ukuran sisi kubus

\begin{tabular}{ccc}
\hline Ukuran Sisi $(\mathrm{nm})$ & $\mathrm{H}_{\mathrm{c}}(\mathrm{T})$ & $\mathrm{H}_{\mathrm{s}}(\mathrm{T})$ \\
\hline 8 & $3.46 \times 10^{-7}$ & $6.15 \times 10^{-7}$ \\
20 & $9.43 \times 10^{-7}$ & $1.24 \times 10^{-6}$ \\
29 & $1.5 \times 10^{-6}$ & $2.4 \times 10^{-6}$ \\
\hline
\end{tabular}

Berdasarkan tabel 4.1 menunjukkan bahwa seiring bertambahnya ukuran sisi kubus, medan koersivitasnya akan semakin besar. Begitu pula pada medan saturasi, yaitu semakin bertambah besar ukuran sisi kubus maka medan saturasi juga semakin besar. Hal ini mengakibatkan magnetisasi yang terjadi semakin besar karena membutuhkan energi yang besar. Besarnya medan koersivitas itu menunjukkan bahwa pada saat sisi kubus besar bahan memiliki energi yang lebih besar untuk termagnetisasi.

\section{KESIMPULAN}

Kesimpulan yang diperoleh dari penelitian mengenai sifat magnetik berdasarkan ukuran kritis bahan $\mathrm{CoPt}$ menggunakan simulasi mikromagnetik, ukuran kritis bahan CoPt yang dianalisis pada grafik hubungan memiliki nilai sebesar $20 \mathrm{~nm}$. Stuktur domain yang terbentuk pada rentang $(8-20) \mathrm{nm}$ adalah single domain dengan energi demagnetisasi yang lebih mendominasi, sedangkan pada multi domain terletak pada interval ukuran sisi kubus sebesar $(29-41) \mathrm{nm}$ dengan energi exchange yang lebih mendominasi. Berdasarkan hasil simulasi yang diperoleh untuk menentukan sisi kritis bahan CoPt sesuai dengan perhitungan secara teori yaitu menggunakan persamaan Brown.

Kurva histerisis untuk zona single domain nilai medan koersivitas $3.46 \times 10^{-7} \mathrm{~T}$, zona transisi nilai medan koersivitas sebesar $9.43 \times 10^{-7} \mathrm{~T}$., sedangkan pada zona multi domain diperoleh sebesar $2.4 \times 10^{-6} \mathrm{~T}$. Bahan CoPt tergolong dalam sifat soft magnet karena memiliki nilai medan koersivitas lebih kecil dari $1 \mathrm{~T}$.

\section{DAFTAR PUSTAKA}

Hosoiri, K., Doi, S., Wang, F., Kuzushima, T., \& Watanabe, T. (2003, 12/20). Microstructure of Electrodeposited Co-Pt Binary Alloy Film for High Density Recording Media. Materia Japan, 42, 908-908. https://doi.org/10.2320/materia.42.908

Mardiansyah, D. (2014). Analisa Sifat Ferromagnetik Material Menggunakan Metode Monte Carlo. Edu Research, 2(2), 65-74.

Nazah, S. (2017). Investigasi Sifat-Sifat Magnetik Alloy Co1-xPtx dan Penentuan Temperatur Curie Berdasarkan Simulasi Mikromagnetik Universitas Jember]. Fisika Fak. MIPA UNEJ

Piramanayagam, S. (2007). Perpendicular recording media for hard disk drives. J ournal of Applied Physics, 102(1), 2.

Sun, X., Jia, Z., Huang, Y., Harrell, J., Nikles, D., Sun, K., \& Wang, L. (2004). Synthesis and magnetic properties of CoPt nanoparticles. J ournal of Applied Physics, 95(11), 6747-6749.

Wahyuningsih, A. E. (2018). Analisis Temperatur Curie Dan Kurva Histerisis Material Alloy Co (1-X) Pt (X) Model Nanocube Dengan Simulasi Mikromagnetik Universitas Jember]. Perpustakaan UNEJ. https://repository.unej.ac.id/bitstream/handle/123456789/90553/Alfia\%20Endah \%20Wahyuningsih-141810201032_.pdf?sequence=1 
Widodo, A. T. (2013). Studi mikromagnetik dinamika struktur domain pada material feromagnetik $\mathrm{Py}, \mathrm{Ni}, \mathrm{Fe}$ dan $\mathrm{Co}$ model nanosphere = Micromagnetic study of dynamic domain structure in ferromagnetic $\mathrm{Py}, \mathrm{Ni}, \mathrm{Fe}$ and $\mathrm{Co}$ nanospheres model Universitas Indonesia]. Depok: Fakultas Matematika dan Ilmu Pengetahuan Alam Universitas Indonesia. http://152.118.24.168/detail?id=20348673\#parentHorizontalTab1

Yani, A., Ridwan, R., \& Mujamilah, M. (2019). SIMULASI HISTERESIS PADA BAHAN FEROMAGNETIK DENGAN MODEL JILES-ATHERTON. J urnal Sains Materi Indonesia, 85-90. 